\title{
Concept Design with a Living Lab Approach
}

\author{
Birgitta Bergvall-Kåreborn \\ Social Informatics \\ Luleå University of \\ Technology \\ Birgitta.Bergvall- \\ Kareborn@1tu.se
}

\author{
Marita Holst \\ Centre for Distance-spanning \\ Technology \\ Luleå University of \\ Technology \\ Marita.Holst@cdt.ltu.se
}

\author{
Anna Ståhlbröst \\ Social Informatics \\ Luleå University of \\ Technology \\ Anna.Stahlbrost@ltu.se
}

\begin{abstract}
Living Labs is a rather new research area and phenomena that introduces new ways of managing innovation processes. The underlying idea is that people's ideas, experiences, and knowledge, as well as their daily needs of support from products, services, or applications, should be the starting point in innovation. This paper illuminates experiences and accumulated knowledge to the area of concept design in an innovation process within a Living Lab. FormIT, a methodology developed for innovation processes within Living Labs is introduced through an illustration of how it has been utilised in a case. The experiences and the method are related to characteristics of Living Labs, and the paper closes with some concluding remarks in relation to concept design in a Living Lab.
\end{abstract}

\section{Background and Introduction}

All over Europe, a new type of innovation milieu is emerging, called Living Labs. The rationale behind these new milieus are to open company boundaries toward their environment and harvest creative ideas and work capabilities existing among different stakeholder groups, such as customers, competitors, providers, and the public in general. As such, it is similar in its approach to different open methodologies, e.g., open innovation [1, 2], crowdsourcing [3, 4] and involving lead users $[5,6]$.

In more detail, a Living Lab is a gathering of public-private partnerships in which businesses, researchers, authorities, and citizens work together for the creation, validation, and test of new services, business ideas, markets, and technologies in real-life contexts. The purpose of a Living Lab is to create a shared arena in which digital services, processes, and new ways of working can be developed and tested with user representatives and researchers. Hence, a Living $\mathrm{Lab}$ is an environment in which people and technology are gathered and in which the everyday context and user needs stimulate and challenge both research and development, since authorities and citizens take active part in the innovation process.

Since Living Labs is a rather new research area and phenomena, the amount of supporting theories for understanding the concept is limited. Further, though there exist a plethora of methodologies, methods, and tools used in individual emerging as well as mature Living Labs, there is a lack of systematic analyses and reflection on their suitability in different contexts and situations [7]. The methodological choices often are based on habit and familiarity rather than on best practice in the field. Thus, Feurstein et al. [7] argue for a structuring of the approaches used in Living Labs in order to gain an overview of what is used and to what extent. While we agree that this is interesting, we argue that it is even more important to reflect on how the methodology and methods used reflect the spirit of the Living Labs approach.

The aim of the paper is to contribute with experiences and accumulated knowledge to the area of concept design in a Living Lab milieu. More precisely, the purpose is to present a methodology called FormIT $[8,9]$ and to reflect on its suitability in a Living Lab milieu and how it harmonies with Living Labs characteristics. In this paper, we focus on the concept design phase of the methodology, since the foundation of failure often seems to be established at the very beginning, even if it is not recognised until the end of the development process [10]. Hence, this is where the conditions for the remaining processes are set. Moreover, it is here we can shift perspective from problems to opportunities and from requirements to needs $[8,9]$.

In the following, we present the concept Living Lab and its key principles. Subsequently, we introduce FormIT, followed by a description of our research method and the case used to illustrate the living practise of FormIT. Thereafter, we discuss and reflect on FormIT's suitability related to Living Labs. The paper ends with some concluding remarks.

\section{Living Labs}

Living Lab started to emerge in the beginning of 2000 [11] and the focus initially was to test new technologies in home-like constructed environments. Since then, the concept has grown, and today one precondition in Living Lab activities is that they are situated in a real-world context. During the design of the concept, Living Labs has been defined as an environment [12, 13], as a methodology [14], and as a system [15]. We do not see these three definitions as contradictory but rather as complementary 
perspectives. Depending on which perspective one takes, certain themes come into focus. With the environment perspective, objects such as technological platform and user communities come to the forefront. With the methodology perspective, processes such as data transfers and methods for user involvement are highlighted. The system perspective puts focus on the relation between the Living Lab as a whole and its interdependent parts. In this paper, we focus on the methodological perspective of Living Labs.

The concept of Living Lab can be interpreted and used as a human-centric research and development approach whereby ICT innovations are cocreated, tested, and evaluated in open, collaborative, multicontextual real-world settings. Additionally, the Living Lab approach not only focuses on involving users in the development processes, it also strives to facilitate the interaction among other relevant stakeholders, such as academia and research organisations, SMEs, business industry, civic sector, ICT professionals, and public partners.

Since Living Labs are a rather new phenomena that emerge in such diverse areas as ICT-development, health services, and rural development, it is a hard concept to define and describe. Due to this, different suggestions for key elements and characteristic have been suggested. See for example [7, 14, 16]. We have chosen the five key principles stemming from the CORELabs project, since it is grounded on a study that is based on the views of ten involved Living Labs [15].

- Continuity: This principle is important since good cross-border collaboration, which strengthens creativity and innovation, builds on trust, and this takes time to build up.

- Openness: The innovation process should be as open as possible, since the gathering of many perspectives and bringing enough power to achieve rapid progress is important. The open process also makes it possible to support the process of user-driven innovation, including users wherever they are and whoever they are.

- Realism: To generate results that are valid for real markets, it is necessary to facilitate as realistic use situations and behavior as possible. This principle also is relevant since focusing on real users, in real-life situations is what distinguishes Living Labs from other kinds of open cocreation environments such as Second Life.

- Empowerment of users: The engagement of users is fundamental in order to bring innovation processes in a desired direction, based on the humans' needs and desires. Living Labs efficiency is based on the creative power of user communities; hence, it becomes important to motivate and empower the users to engage in these processes.

- Spontaneity: In order to succeed with new innovations, it is important to inspire usage, meet personal desires, and fit and contribute to societal and social needs. Here, it becomes important to have the ability to detect, aggregate, and analyse spontaneous users' reactions and ideas over time.

In comparing Living Labs to traditional systems development, we can identify a number of differences and a few similarities. In relation to continuity, both Living Labs and systems development believes that good cross-border collaboration takes time to build up. Therefore, we do not see a clear difference between Living Labs and systems development in this aspect.

When it comes to openness, the two approaches differ more significantly. Here, Living Labs is influenced strongly by "open innovation" [1] and, as such, Living Labs believes strongly that organisations should combine internal and external ideas into the development process. Systems development often takes the opposite approach, limiting the number of inflows into the development process, with the argument that it becomes too complex and expensive to involve all stakeholders.

Perhaps the difference between the two approaches becomes clearest in relation to the concept realism. In Living Labs, the approach is for real-world contexts, real users, and real use situations [12]. This means that users are involved in their own private contexts all day round. Hence, when a Living Lab approach is applied, the aim is to create as authentic use situations as possible. In traditional user involvement processes, users can be asked to use a system or device in a so-called field study. In these processes, the user is requested to use the device in a context in which the researcher, or developer, can observe users' actions and how the technology impacts them [17]; hence, the use situation is not fully authentic.

Whether there is a difference between the two approaches when it comes to empowerment is more difficult to judge. The reason for this is that there are a number of user involvement methodologies [18] that all can be argued as rather traditional but that differ greatly among each other. Despite this, it still is possible to discern a difference in the argumentation for user involvement between Living Labs and these traditional user involvement methodologies. Within Living Labs, all involved stakeholders, even end users, are seen as partners. In systems development end users seldom are seen as partners but rather as actors, even though their organisation might be viewed as partners.

Finally, in relation to the last key principle, spontaneity, we do not find any apparent differences. Instead, we have identified an important difference between the two approaches that cannot be linked to the key principles. This is the relation to academia. In Living Labs, most activities are carries out in close relation to academia, while this often is not the case within most systems development projects. By this, Living Labs has the possibility to research both more theoretical and more practical matters. More precisely, research is carried out within the Living Labs environment, while in systems development it is carried out by academia in relation to a company, if at all. 


\section{FormIT - an Illustration of a Living Lab Methodology}

In this section, we present the framework of ideas and characteristics of FormIT before we introduce the general shape of FormIT in order to give a holistic view of the methodology. The kernel of this paper is concept design, and this part of FormIT therefore will be presented in more detail through an illustration of a case later in this paper.

\subsection{Framework of Ideas}

FormIT is inspired by three theoretical streams: Soft Systems Thinking, Appreciative Inquiry, and NeedFinding. From the first stream, Soft Systems Thinking $[19,20]$, the assumption that changes can occur only through changes in mental models is utilised. This implies that we need to understand both our own as well as other stakeholders' worldviews, and we need to be clear about our interpretations and the base on which they are made. The second stream, Appreciative Inquiry [21-24], has encouraged us to start the development cycle by identifying different stakeholders' dreams and visions of how IT can improve and support the lives of people. This includes a focus on opportunities, related to specific trends, contexts, or user groups, and on the positive and lifegenerating experiences of people [25, 26].

This way of thinking is aligned closely with the philosophy behind soft systems thinking, since it also highlights the importance of people's thoughts about themselves and the world around in a design situation. Hence, instead of starting the process by searching for problems to solve in a situation, we identify what works well and use this as a basis for design.

The third stream, NeedFinding, has two different inspirational sources. The NeedFinding concept, as such, and its motivation finds its origin in a paper by Patnaik and Becker [27]. Patnaik and Becker argue that the main motivators for the NeedFinding approach are that needs are not influenced highly by trends; hence, they are more long lasting. The needs generation process, on the other hand, is inspired by Kankainen and Oulasvirta [28] and Tiitta [29]. These authors inspire us to focus on user needs throughout the development process, and to use these as a foundation for the requirement specification.

\subsection{Characteristics of FormIT}

Grounded in these three theoretical streams, FormIT enables a focus on possibilities and strengths in the situation under study; which is fundamentally different from traditional problem-solving approaches. In our perspective, identifying opportunities is the basis for appreciating needs since needs are opportunities waiting to be exploited [25, 26]. Hence, FormIT strongly stresses the importance of the first phase in the concept design cycle, usually referred to as analyses or requirements engineering. Since this phase creates the foundation for the rest of the process, errors here becomes very hard and expensive to correct in later stages. This also is the phase in which users can make the strongest contributions by actually setting the direction for the design, rather than mainly responding to (half finished) prototypes. Since users' needs and requirements can change as users gain more knowledge and insights into possible solutions, it is important to reexamine their needs continually and make sure they correlate to given requirements.

In accordance, the FormIT method is iterative and interaction with users is an understood prerequisite. The idea is that knowledge increases through iterative interactions between phases and people with diverse competences and perspectives $[30,31]$. In this way, knowledge increases through dialogue among participants. The idea is that the cross-functional interaction enables the processes of taking knowledge from one field to another to gain fresh insights, which then facilitates innovative ideas. The shared understanding of the situation that evolves in this process informs and enriches the learning processes and thus facilitates changes in perspective and lead towards innovative design processes. This, in turn, increases our qualifications to design IT systems that answer to user needs [26].

\subsection{General Shape of FormIT}

The FormIT process can be seen as a spiral in which the focus and shape of the design becomes clearer, while the attention of the evaluation broadens from a focus on concepts and usability aspects to a holistic view on the use of the system; see figure 1 .

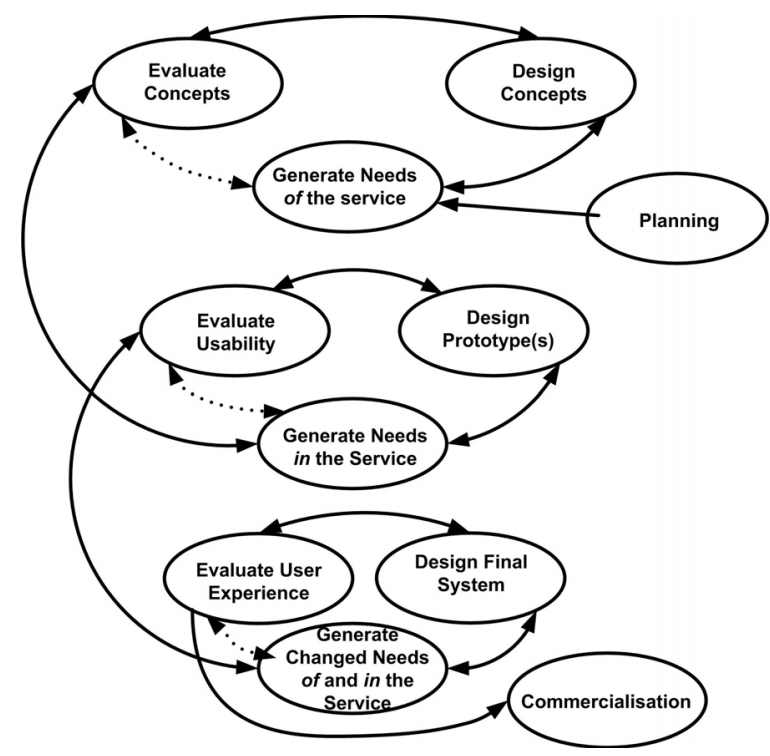

Figure 1. The FormIT Process for Systems
Development

In this process three phases - Generate Needs, Design, and Evaluate - are repeated in three iterative cycles. The first cycle is called Concept Design, the second Prototype Design, and the third Final System 
Design. The name of the cycle indicates the expected output of each cycle. Besides these three cycles, two additional phases are included in the figure. The first is planning, seen in the upper right hand corner of the figure, and the second is commercialisation. Focus of this paper is concept design, which is managed in the first cycle, illustrated in the upper level of figure 1.

\section{Research Method}

In this study, we have chosen an action research approach. Action research means that one enters a realworld situation with the aim of both improving it and creating knowledge $[32,33]$. This fits well with the dual role we have had in this study. Our responsibility was to identify opportunities that could improve the situation for users in remote rural areas as well as to develop FormIT further through reflection on our experiences of applying the methodology in this particular situation. Action research also is a well suited methodology for the Living Lab, since both approaches emphasise interaction between theory and practice, involve many different stakeholders with distinct roles relevant in the situation, and highlight the importance of constant reflection in order to follow wherever the situation leads.

Action research also is an established method within social sciences, including information systems $[34,35]$, and is thought to produce highly relevant results because it is grounded in practical action and aims to solve immediate problem situations while informing theory. Baskerville and Wood-Harper [34] even argue that "action research is one of the few valid research approaches that researchers can legitimately employ to study the effects of specific alterations in systems development methodologies" (p. 240).

The data gathering that took place in the case is mainly a part of the aim of improving the situation. As such, it will be integrated and reported in the Case section. The research part is our reflection on how suitable FormIT is within a Living Lab approach. It therefore will be presented in the discussion.

\section{Case}

The case in focus for this paper is called Cross Border Cooperative Pilots (CroCoPil). CroCoPil was an Interreg IIIA NORTH project with partners from northern Norway, Sweden, and Finland. The project had its background in the new technologies that are evolving and build on dynamic and mobile structures rather than fixed infrastructures. Among these technologies, we find high speed wireless networks, delay tolerant networking, peer-to-peer networking, digitalisation of mobile phone systems, and possibly new satellite systems. Together with this shifting technology management from fixed to dynamic and mobile connectivity, a potential appears for rural and remote areas to become involved and to take a lead in forming the new technologies and the requirements that they are to meet.
The overall objective of the CroCoPil-project was to apply user needs as a basis for technology development, adaptation, and evaluation in order to create services that could reduce the digital divide between rural and urban areas, create cross-border business opportunities between the northern parts of Finland, Sweden, and Norway and establish cross border cooperation in several other fields.

In the following, the case will be illustrated and integrated with a more detailed description of the planning phase and the phases contained in the first cycle of FormIT, focused on concept design.

\subsection{Planning.}

The planning phase of FormIT includes deciding on the overall project team and discussing such issues as the purpose of the project, the specifics of the context, important constraints and relevant methodologies, and methods for the project as a whole. This is important since it facilitates the creation of common perspectives as well as understanding differences in values around these issues [36, 37]. This process can be difficult to accomplish since project participants usually have different opinions and want to make contributions to many different areas.

In CroCoPil, the overall project team comprised people from all three countries, including participants from academia, private companies, public organisations, and potential end-user groups. Common for all end-user groups was that they should be field workers located in remote rural areas. The more detailed definition and grouping of end users was done in the concept design cycle. In the planning phase, it was decided to perform the interviews in the users' work premises.

The methodology was decided to be FormIT, since this has been developed especially for Living Lab milieus and e-services. Since the methodology was not known to all participants, educational workshops were provided and a semi-detailed guideline for the concept design cycle was distributed to all relevant participants in the three countries.

\subsection{Phase 1. Generate Needs.}

In the first phase of Concept Design, we start by designing the team. When the team has been designed, a number of need generating sessions are held, with the focus of identifying strengths and best practices by stimulating user participants to provide rich and appreciative narratives about past and present situations $[25,26]$. Based on these narratives, the users then are asked to shift focus from appreciating "what has been" and "what is" to dreaming about the future and "what might be." From the stories of best practice and the dreams and wishes of the users, needs are generated and prioritised. The main challenge in the Generate Needs phase usually is to help people alter their mental frame of mind from a problem perspective to an affirmative perspective, and to make them talk about what works well instead of what is 
unsatisfactory. When it comes to dreaming about the future, the challenge is to help people let go of the status quo and look beyond their present knowledge of currently existing technological possibilities [8, 9].

In CroCoPil, the team in each country consisted of researchers, system developers, and user participants from private companies and pubic authorities.

Following the FormIT methodology, need generating sessions were held in all three countries. Four focus group interviews, two pair interviews, and two individual phone interviews were performed (three focus group interviews in Sweden with reindeer herders, rangers, and tourist companies, two pair interviews in Norway with police and rangers and one focus group interview with reindeer herders, and finally, two individual phone interviews in Finland with tourist companies and home care assistants). To sum up, 24 persons (three women) ages 35-60, contributed with their narratives. The interviews lasted $1 \frac{1}{2}-2^{1 / 2}$ hours, and one moderator and one assistant from the research group led each interview, with exception of the phone interviews, which were performed as one-to-one interviews. All interviews, except the phone interviews, were conducted in the user's own environment.

The results from the interviews were transcribed and analysed. We used a method for analysis that takes it through two phases, a vertical and a horizontal analysis [38]. No themes were decided on beforehand; instead, we searched for statements that indicate a need. This type of analysis often is called open analysis or qualitative analysis. In the vertical analysis, each interview is analysed individually as a way to generate needs. Thereafter, the generated needs in all interviews are compared and clustered into themes in the horizontal analysis.

The analysis showed that some overall needs were shared by all groups, e.g., communication and safety, while there were significant differences in needs between groups and countries when we analysed the needs in more detail.

A good example of an overall need is to be able to communicate, as part of their job (or privately), even though they are far out in the wilderness; this was shared among all respondents. In these rural areas, there is very poor connectivity for mobile phones and no Internet access. Participants described situations in which they kept several different communication tools, such as NMT, GSM and satellite telephones. As the work of all these groups keep them out for days or weeks, they all need to communicate both with colleagues and with their families. Another related shared need is that the communication tool must be small, easy to carry, stable for coldness, water, and bumpy travel, while battery capacity must be large.

As mentioned above, if we look more into detail, communication needs differed significantly between groups and countries. For example, reindeer herders needed to be able to communicate continuously in real time during their work coordinating the reindeer herd. Tourist guides had quite different communication needs. E-mail was their main communication line with potential customers. Otherwise, they wanted to keep the wilderness silent, quite in contradiction to the other user groups. The reason for this was that they did not want their customers to have connectivity, since the silence was part of their product. The rangers usually work alone and need to take notes of what they observe and what they do as they travel across their working area. Hence, they need to send in reports, and also to communicate with colleagues regularly.

After obtaining a rich picture of different stakeholders or user groups, their behaviour, attitudes, and values in the first phase, the needs are translated into concepts. As a result, the focus for the work shifts from the Generate Needs phase to the Design phase. Hence, the findings from the need generating ${ }^{1}$ form the basis for concept design in the next phase. More details of phase 2 are found in the next section.

\subsection{Phase 2. Design Concepts}

The design phase is the most innovative phase in the concept design cycle, since this is where all collected data is clustered in different ways and seen from different perspectives in order to construct innovative and relevant concepts. Therefore, cooperation between different stakeholders is important to ensure that knowledge is shared both across and within competence areas. Since many developers and engineers are unfamiliar with this way of working, they often want to skip this part and go directly to the requirements and specifications, the second cycle of the FormIT model. We have found, however, that to ensure that the final solution responds to users' needs and doesn't merely reflect what is technically possible; a close interaction between people with different competences and different focuses on the development process is needed.

Hence, in this phase, the focus is to design and develop innovative service concepts on the basis of the generated needs and requirements from the earlier phase. At this point, the generated needs, as well as identified strengths and dreams, form the basis for the vision of the service/s that take form. The ideas can be elaborated on and expressed both textually, in the form of key concepts, personas, or scenarios, and pictorially, in the form of visual scenarios (rich pictures), or mockups of the system/s. The concepts need to be detailed enough for the users to understand the basic objective and functions of the future solution.

In the second phase of CroCoPil, concepts were designed within each participating country but based on the need generating data from all countries. People from all participating groups of the national project teams held several virtual and physical meetings in which the results from phase 1 were discussed. From the discussions, several concepts evolved, meeting user needs. In meetings, sketches, figures, or models were

\footnotetext{
1. In this phase, the safety needs, communication possibilities, exchange of experiences, mobility (independence), monitor and control (order), knowledge sharing, social contact, coordination, freedom (being out in the nature) and economy (effectiveness, efficiency) were identified.
} 
presented and discussed as ways to modify and design the concepts. Finally, 14 concepts $^{2}$ were designed, and from these three were chosen for evaluation in the third phase. As an illustration of a concept designed in the CroCoPil project, Seamless Office is outlined in the following.

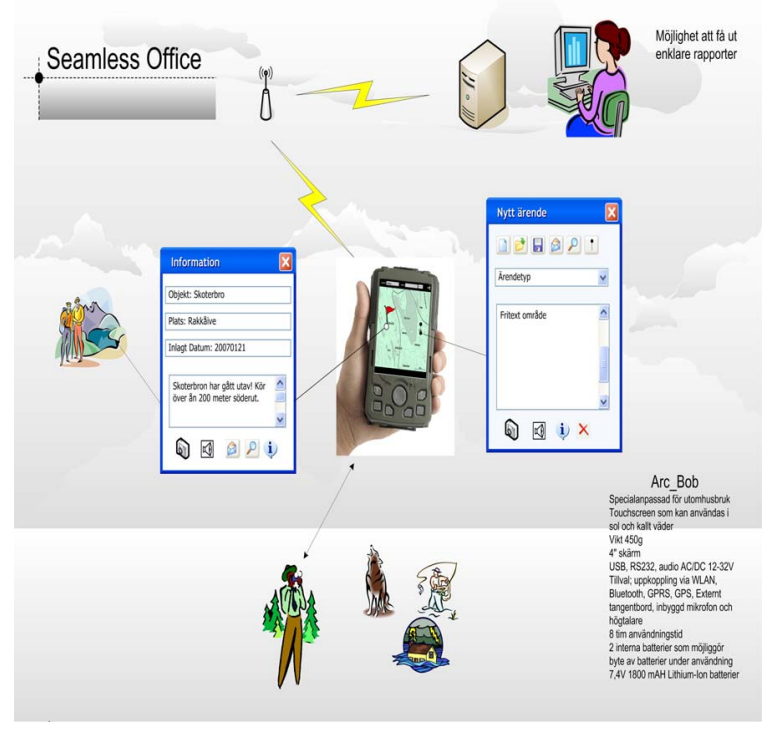

Figure 2. Seamless Office

The Seamless Office concept was constructed as a rich picture $[19,20]$; see figure 2 . This concept was designed mainly to represent the rangers' need of wireless transfer of data while out in the field. They needed to store all their collected data immediate in the database. The dream was to have a clear screen when coming back to the office after some days out in the field, thus being able to decrease their office time.

The idea of Seamless Office was to gather many functions in one gadget, to make it possible to store data in the device, and to be able to send the data by means of wireless networks over the Internet directly from the field, or merely connect it to the computer and transfer the data when in office.

To illustrate the concept, we used the PDA ArcBob, since it answered to the clearly outspoken needs of a robust and "multi-talented" gadget. ArcBob is a lightweight and advanced PDA with many functions, such as phone, GPS, calculator, and with a socket fitting the snowmobile, making it possible to charge the battery. To this were added the functionalities of, e.g., interactive maps and database connections.

In relation to project as a whole, there also were needs that were not met by any of the 14 concepts developed. For example, the need to have continuous real-time communication around the reindeer herd was not met by any of the suggested concepts. Neither was

2. Home Care Diary, Online Service Warehouse, Travel Diary, GeoBlog, Seamless Office, Specialised Field Device, Ad Hoc Relay Stations (ad hoc networks), Extending Sensing (sensor), Delayed e-mail and web-access, Information Packets, Calculation Application, Webb Meeting Place, Webb School, Interactive Map. the safety need pervasive in the different concepts, even though it was a frequently mentioned need. This was due to technological constraints at the time. In the next section we will illustrate the process of evaluating concepts with users.

\subsection{Phase 3. Evaluate Concepts.}

In the third phase of FormIT, users are invited and encouraged to give their impressions of a concept that has been constructed to represent their needs. In this process, the evaluation is combined with the aim to generate new and unexplored needs, or to modify needs. This is an important part of FormIT, since the aim is to create a final solution with functionality that represents the generated user needs.

In the concept evaluation in CroCoPil, we returned to the Swedish users (reindeer herders (seven men) and tourist companies (one woman) and rangers (two men) whom we met in the first phase), and evaluated the chosen three concepts in focus group interviews. Since only one tourist company representative and two rangers could participate, they were interviewed together at the hotel owned by the tourist company. The rangers worked in the same area so they were acquainted with each other. The evaluation comprised focus group interviews that took about $1 \frac{1 / 2}{2}$ hours and had the aim to discuss and test the concepts that had been chosen for evaluation (GeoBlog, Seamless Office and HomeCare Diary). The concepts were presented as a scenario, a Rich Picture, and a use-case, i.e., as visual narratives.

The interviews were designed so that the groups were introduced to the concept in the form of, e.g., a scenario. They then were asked to respond spontaneously. When the discussion was finished, we discussed how the concept was related to needs generated in phase 1 . Thereafter, the next concept was introduced.

We continue with the Seamless Office as an example. This concept was designed based mainly on the rangers' need of data storage and wireless transfer of data while out in the field. The most intense reactions on this concept came from the reindeer herders who could visualise new ways of working.

One example of this is that planning and preparing for building new reindeer herd fences could be done ahead. Instead of doing the entire job in the summer, they envisioned how they could plan and prepare a major part of their work during winter. Using snowmobiles, they could mark the area that should be fenced and at the same time calculate the circumference of the fence and where the poles should be placed. Using the GPS coordinates, they could identify where to leave piles of poles; then, in the summer, they only had to do the actual building of the fence. Additionally, they could calculate things such as the number of poles needed and the cost of the fence.

The reaction among reindeer herders was interesting because the first need generating interview had not identified these dreams to rearrange work between seasons. Here, we learned a lot more about 
their work and needs at the same time as they learned about new opportunities. Hence, we acknowledge the significance a mock-up or scenario could have to fuel the discussions, as well as the importance of an iterative and interactive process.

Rangers also were positive; this answered to their needs. A good map and you just click on the screen and write your information and save it. It also would be possible to save data about their route, facilitating their work.

When we discussed needs in relation to this concept, participating reindeer herders found it interesting to see how the concept opened up the discussion about coordination of work. They saw many new ways to do their work with the help of technology. It was found that the concept also answered to the need of economy, communication, mobility, and knowledge sharing. After the evaluation meetings, data from the interviews were compiled in the same way as in phase 1 .

In FormIT, the focus shifts again, this time from the evaluation phase of the first cycle to generate needs in the next cycle. However, this work will be part of another paper. In this paper, we now will discuss the lessons learned from the whole first cycle of FormIT. A lot was learned from the CroCoPil project, both when it comes to reactions on the concepts and in relation to methods for concept design processes in a Living Lab.

\section{Discussion}

In this section, we discuss FormIT characteristics in relation to the five key principles of Living Labs. Examples and illustrations are given from the CroCoPil project.

\subsection{Continuity}

The principle of continuity highlights the importance of good cross-border collaboration that builds on trust, since it strengthens creativity and innovation. However, trust takes time to build up.

In FormIT, the continuity principle is inherent in many different ways. The most visible is the flow from needs and concept to prototypes and finished products. Here, the iterative process strengthens this continuity through a constant interaction back and forth between phases and cycles. We therefore argue that continuity within a Living Lab methodology is just as important as the continuity between collaborative partners.

In the CroCoPil case, we decided to include and cooperate with the same user group throughout the concept design cycle. From a continuity perspective, this is very important in order to verify the relevance of the designed concepts and their relation to the needs of the user group. Additionally, in concept design, understanding, and to some extent constructing, needs is a crucial activity, since a service or a product that does not meet user needs will not succeed in the market [39].

\subsection{Openness}

The principle of openness emphasises that the innovation process should be as open as possible. The idea is that multiple perspectives bring power to the development process and achieve rapid progress. The openness supports the process of user-driven innovation.

Open inclusion of multiple stakeholders and perspectives is a key characteristic of FormIT and is illustrated in CroCoPil, where the teams consisted of people from academia, private companies, public organisations, and potential end-user groups. We included many different stakeholders, both on the project level and on the national level. It is unclear if this resulted in a more rapid progress or not. We can conclude, however, that the process resulted in more concept ideas than anticipated, fourteen instead of nine.

In relation to the last part of the principle, that inclusion of many different stakeholder perspectives supports the process of user-driven innovation, we want to raise a word of warning. It is important to recognise that inclusion of multiple stakeholders does not guarantee a user-driven innovation process. Of course, this depends on the definition taken and, here, numerous diverse definitions exist [40].

We take a somewhat radical view by arguing that the use of the concept should be delimited to processes in which the users actually take the lead and drive the innovation process forward. This radical view is necessary for the concept to bring an air of innovation into the field of IS innovation, since user participation has such a long tradition within this field, especially within the Nordic countries [41, 42].

Hence, we argue that user-driven innovation needs to be aligned with the concept "design-by users," and that we should not include concepts such as "designwith" or "design for users" here [43]. If we want a concept that brings all user involvement concepts under the same umbrella, we suggest the user-centric concept. By differentiating clearly between general concepts of user participation and concepts that want to take user participation one step further, we have the opportunity for critical reflection both in relation to the concepts and their use.

If we scrutinise FormIT critically, we see that while we strive for user-driven innovation, we have not reached this position yet. In the CroCoPil project, we adapted a user-centric approach based on the principle of design with users. This also seem to be the maturity level among many Living Lab projects [44].

One important element in open innovation is the openness of the content produced within innovation processes [2]. This type of openness, however, is not expressed explicitly in the definition of the openness principle for Living Lab. We believe that this is an important part and therefore should be highlighted within the principles of Living Lab. In FormIT, we strive for this type of openness as far as possible; in CroCoPil, all concepts designed in the concept design 
cycle were open to anyone, both within and outside the project team, since they were published on the project home page.

\subsection{Realism}

Realism is one of the principles that clearly separate Living Lab from traditional systems development, as well as other kinds of open cocreation environments, such as Second Life. The principle highlights the necessity to facilitate realistic use situations and behaviour as possible in order to generate results that are valid for real markets.

As the principle suggests, realism can exist on many different levels and in relation to many different elements, such as contexts, users, use situations, technologies, and needs.

When it comes to facilitating realistic use situations as possible, two different approaches can be observed, rather easily, in relation to Living Labs. In the first approach, environments for testing and evaluation of products or services are created in ways that are similar to the real world [11]; in the second approach, products and services are tested and evaluated in users real world environments [44].

FormIT takes the realism aspect one step further with the aim of involving users already in the concept design cycle, since this is where the conditions for the remaining processes are set. It is here that users can make the strongest contribution to a product or service by setting the direction for the design, rather than merely responding to prototypes in a test.

This is illustrated in the CroCoPil case, in which it was decided to perform the interviews in the users' work premises. Even if these premises were part of the real-world working situation of the user-groups, they constituted a limited part of their work since they spent most of their working time out in the field. Common for all end-user groups was that they should be field workers located in remote rural areas. So, it would have been even more authentic if the need generation and evaluation had been carried out there. However, this was considered impractical and therefore not acted out.

\subsection{Empowerment of Users}

The key element in the empowerment principle is to base innovations on humans' needs and desires, and to utilise the creative power of user communities.

Empowerment of users also is a key characteristic in FormIT and is visible in many different ways. Firstly, users and other stakeholders are seen as partners in the innovation process, not just as codesigners, which is common in most systems development projects. Inherent in being a partner, from an end-user perspective, is the power of choice. They always can choose if, when, and to what extent they want to participate.

Secondly, including potential end users guarantees participation and facilitates involvement. However, in our view, influence is the key to empowerment, that is, if user needs and ideas can be traceable in the concepts, prototype, and finished product. FormIT's iterative process between phases and between cycles makes it possible for users to judge whether their participation and involvement contributed to and influenced key deliverables.

In the evaluation phase of CroCoPil, three concepts were presented to the Swedish user groups. The concepts were discussed in relation to needs and values of the groups. During these discussions, the user groups confirmed that the concepts fulfilled some of their needs, such as needs related to "economy" and "communication." It also highlights generated needs that have not been represented in any concept. To discuss this and the reasons for their exclusion also is important from an empowerment perspective.

\subsection{Spontaneity}

In order to succeed with new innovations, it is important to inspire usage, meet personal desires, and contribute to societal and social needs as outlined in the spontaneity principle. Here, it becomes important to have the ability to detect, aggregate, and analyse spontaneous users' reactions and ideas over time.

When evaluating concepts in FormIT, the concepts are visualised for the users without any formal presentation. This gives the users the chance to interpret the concepts in their own way without being influenced by our intentions. Then the users present their interpretation to the rest of the group and different interpretations are discussed and related to each other. This allows spontaneous reactions and new ideas to be generated.

When evaluating the concept "The Seamless Office," the discussion among reindeer herders first was relatively passive and silent until they understood the functionality of ArcBob and how it related to their needs. This turned the evaluation session into a spontaneous, dynamic, and highly creative group discussion. Suddenly, the users could give numerous examples of how they would use the seamless office in their work situation and the value this would add. From these discussions, we also could generate new ideas and needs.

\section{Concluding Remarks}

In this paper, we have presented a methodology called FormIT and reflected on its suitability to the Living Lab approach, aiming to contribute to concept design in this area with experiences and accumulated knowledge.

We find that the Form-IT methodology and its concept design cycle fits very well with the basic idea of Living Labs. The methodology stresses user involvement in real world contexts. However, we find that there still is much work to be done before the concept design process truly meets the vision of taking place utterly in the users' real world contexts throughout the whole innovation process, as well as being truly user-driven. 
In line with Living Lab characteristics, FormIT also strongly emphasises the importance of grounding the concepts in the needs and desires of users. In FormIT, the whole concept design cycle builds on user needs through constant iterations between the three phases in the cycle. Furthermore, the learning perspective inherent in FormIT fits well with the Living Labs characteristic of including many different stakeholders from academic, public, and private organisations together with end users.

Finally, some important issues have been identified for the continuing development of FormIT: firstly, to develop FormIT into a methodology that supports our view on user-driven innovation in better ways; secondly, to develop methods and tools that make it possible to capture users' spontaneous ideas and reactions on changes in, for example, their contexts, technology, and activities; and thirdly, to enable further user participation based on their own initiative, which in turn would lead to a stronger relation to their real world situation and empower the users, since they are in control of the situation.

\section{Acknowledgements}

CroCoPil was financed by Interreg IIIA NORTH, North Calotte Council, and regional stakeholders; Innovasjon Norge, Troms Fylkekommune, Swedish State Provincial Office in Norrbotten, and Regional Council of Lapland (Lapinliitto).

We also would like to thank the anonymous reviewers who gave valuable comments, which has helped us to improve the paper.

\section{References}

1. Chesbrough, H., Open Innovation: The New Imperative for Creating and Profiting from Technology. 2003, Harvard: Harvard Business School Press.

2. Chesbrough, H. and M. Appleyard, Open Innovation and Strategy. California Management Review, 2007. 50(1): p. 57-76.

3. Brandel, M., CROWD SOURCING: Are You Ready to Ask the World for Answers? Computerworld, 2008. 42(10): p. 24-26.

4. Hempel, J., Tapping the Wisdom of the Crowd. Business Week Online, 2007: p. 27.

5. Von Hippel, E., Lead User: A Source of Novel Product Concepts. Management Science, 1986. 32(7): p. 791805.

6. Von Hippel, E. and R. Katz, Shifting Innovation to Users via Toolkits. Management Science, 2002. 48(7): p. 821-833.

7. Feurstein, K., et al., Living Labs: A New Development Strategy, in European Living Labs - A New Approach for Human Centric Regional Innovation, J. Schumacher and V.P. Niitamo, Editors. 2008, Wissenschaftlicher Verlag: Berlin. p. 1-14.

8. Bergvall-Kåreborn, B., M. Holst, and A. Ståhlbröst, Creating a New Leverage Point for Information Systems Development, in Advances in Appreciative Inquiry - Designing Information and Organisations with a Positive Lens, M. Avital, R. Boland, and D. Cooperrider, Editors. 2008, Elsevier. p. 75-95.

9. Ståhlbröst, A. and B. Bergvall-Kåreborn, FormIT - An Approach to User Involvement, in European Living Labs- A New Approach for Human Centric Regional
Innovation, J. Schumacher and V.P. Niitamo, Editors. 2008, Wissenschaftlicher Verlag: Berlin. p. 63-76.

10. Pitts, M.G. and G.J. Browne, Improving Requirements Elicitation - an Empirical Invistigation of Procedural Prompts. Information Systems Journal, 2007. 17(1): p. 89-110.

11. Markopoulos, P. and G.W.M. Rauterberg, Living Lab: A White Paper, in IPO Annual Progress Report. 2000. p. 53-65.

12. Ballon, P., J. Pierson, and S. Delaere. Open Innovation Platforms For Broadband Services: Benchmarking European Practices. in in 16th European Regional Conference. 2005. Porto, Portugal.

13. Schaffers, H., et al., Exploring Busniess Models for Open Innovation in Rural Living Labs, in Proceedings of the 13th International Conference on Concurrent Enterprising. 2007: Sophia-Antipolis, France. p. pp 49-56.

14. Eriksson, M., et al. State-of-the-art and Good Practice in the Field of Living Labs. in in Proceedings of the 12th International Conference on Concurrent Enterprising: Innovative Products and Services through Collaborative Networks. 2006. Milan, Italy.

15. CoreLabs., Living Labs Roadmap 2007-2010: Recommendations on Networked Systems for Open User-Driven Research, Development and Innovation, in Open Document. 2007, Luleå University of Technology, Centrum for Distance Spanning Technology: Luleå. p. 1-61.

16. Mulder, I., et al. Towards Harmonized Methods and Tools for Living Labs. in eChallenge2007. 2007. Hauge, The Netherlands.

17. Preece, J., Y. Rogers, and H. Sharp, Interaction Design: Beyond human-computer interaction. 2002, New York: John Wiley \& Sons, Inc.

18. Bekker, M. and J. Long, User Involvement in the Design of Human-Computer Interactions: Some Similarities and Differences between Design Approaches, in People and Computers XiV: Proceedings of the HCI 2000, S. McDonald and G. Cockton, Editors. 2000, Springer: New York. p. 135147.

19. Checkland, P., Systems Thinking, Systems Practice. 1981, Chichester: John Wiley \& Sons.

20. Checkland, P. and J. Scholes, Soft Systems Methodology in Action. 1990, Chichester: John Wiley $\&$ Sons.

21. Cooperrider, D.L. and M. Avital, eds. Advances in Appreciative Inquiry, Constructive Discourse and Human Organisation. Vol. 1. 2004, Elsevier: Oxford.

22. Cooperrider, D.L. and D. Whitney, Appreciative Inquiry - A Positive Revolution in Change. 2005, San Francisco: Berrett-Koehler Publishers.

23. Cooperrider, D.L., D. Whitney, and J.M. Stavros, Appreciative Inquiry Handbook. 2005, San Francisco: Berrett-Koehler Publishers.

24. Norum, K.E., Appreciative Design. Systems Research and Behavioral Science, 2001. 18: p. 323-333.

25. Holst, M. and A. Ståhlbröst, Enriching the Process of Appreciating Needs with Storytelling. International Journal of Technology, Knowledge and Society., 2006. Vol. 2(4): p. 61-68.

26. Ståhlbröst, A. and M. Holst, Appreciating Needs for Innovative IT Design. International Journal of Knowledge, Culture and Change Management, 2006. Vol. 6.

27. Patnaik, D. and R. Becker, Needfinding: The Why and How of Uncovering People's Needs. Design Management Journal, 1999. 10(2): p. 37-43. 
28. Kankainen, A. and A. Oulasvirta. Design Ideas for Everyday Mobile and Ubiquitous Computing Based on Qualitative User Data. in User Interface for All, LNCS 2615. 2003. Berlin: Springer-Verlag.

29. Tiitta, S. Identifying elderly people's needs for communication and mobility. in Include. 2003.

30. Holst, M. and A. Mirijamdotter. Framing MultiDisciplinary Teams: Sense Making Through the POMmodel. in 12th Annual CPTS Working Conference Integrating Visions of Technology. 2006. Maarssen, The Netherlands.

31. Mirijamdotter, A., M.M. Somerville, and M. Holst, An Interactive and Iterative Evaluation Approach for Creating Collaborative Learning Environments. The Electronic Journal of Information Systems Evaluation (EJISE), 2006. 9(2): p. 83-92.

32. Baskerville, R.L. and A.T. Wood-Harper, Diversity in Information Systems Action Research Methods. European Journal of Information Systems, 1998. 7: p. 90-107.

33. Checkland, P.B. and S. Holwell, Action Research: Its Nature and Validity. Systemic Practice and Action Research, 1998. 11(1): p. 9-21.

34. Baskerville, R.L. and T.A.T. Wood-Harper, A Critical Perspective on Action Research as a Method for Information Systems Research. Journal of Information Technology, 1996. 11: p. 235-246.

35. Jönsson, S., Action Research, in Information Systems Research: Contemporary Approaches and Emergent Traditions, H.-E. Nissen, H.K. Klein, and R. Hirschheim, Editors. 1991, North-Holland: Amsterdam. p. 371-396.
36. Holst, M., Enabling Boundary-Crossing Collaboration for Innovation: Issues for Collaborative Working Environments, in Business Administration and Social Sciences. 2007, University of Technology: Luleå.

37. Ståhlbröst, A., A. Mirijamdotter, and B. BergvallKåreborn. Needs and Accommodation in Evaluation Design. in Proceedings of 12th European Conference on Information Technology Evaluation, ECITE 2005. 2005. Turku, Finland.

38. Thomsson, H., Reflexiva intervjuer. 2002, Lund: Studentlitteratur.

39. Jobber, D., Principles and Practice of Marketing. 1998, London: McGraw-Hill Publishing Company.

40. Wise Hansson, E., Understanding User-Driven Innovation. 2006, Tema Nord: Copenhagen. p. 1-33.

41. Bansler, J., Systems Development Research in Scandinavia: Three Theoretical Schools. Scandinavian Journal of Information Systems, 1989. 1: p. 3-20.

42. Iivari, J. and K. Lyytinen, Research on Information Systems Development in Scandinavia: - Unity in Plurality. Scandinavian Journal of Information Systems, 1998. 10(1\&2): p. 135-185.

43. Bergvall-Kåreborn, B. and A. Ståhlbröst. Participatory Design- One Step Back or Two Steps Forward. in Participatory Design Conference. 2008. Bloomington, Indiana.

44. Schumacher, J. and V.P. Niitamo, eds. European Living Labs - A New Approach for Human Centric Regional Innovation. 2008, Wissenschaftlicher Verlag: Berlin. 